\title{
Knee disease in juvenile idiopathic arthritis (JIA): correlation between clinical and ultrasonographic findings M McCarron*1, M Wray ${ }^{1}$, L Pascoli ${ }^{1}, \mathrm{C} \mathrm{McAllister}^{1}$ and M Rooney ${ }^{2}$
}

Address: ${ }^{1}$ Rheumatology, Musgrave Park Hospital, Belfast, UK and ${ }^{2}$ Musculoskeletal Research Group, Queen's University, Belfast, UK

* Corresponding author

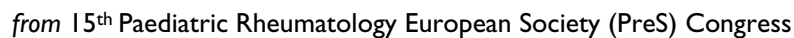

London, UK. 14-17 September 2008

Published: 15 September 2008

Pediatric Rheumatology 2008, 6(SuppI I):P95 doi:I0.I I86/I546-0096-6-SI-P95

This abstract is available from: http://www.ped-rheum.com/content/6/SI/P95

(C) 2008 McCarron et al; licensee BioMed Central Ltd.

\section{Background}

There is increasing evidence that ultrasound (US) scanning is more accurate than clinical examination in detecting effusions in adults. We wished to compare clinical and ultrasonographic findings in knee joints of children with JIA.

\section{Methods}

We are undertaking a five year prospective study of children with newly diagnosed JIA who have knee involvement. Review is three monthly with clinical assessment and US of knee(s) at each visit. Knee swelling is graded 04. US scans were performed by an experienced rheumatologist MR using a Sonosite 180 Plus (L38 5-10 MHZ linear transducer) or Esaote MyLab25 scanner (LA523E 7.5-12 MHZ linear transducer). The scans have been scored independently by 2 observers unaware of the clinical findings (graded 0-3).

\section{Results}

48 children have been recruited and to date, 25 have been followed for 2 years. To date 124 scans have been scored for effusions and synovial hypertrophy. There was good correlation between clinical and US scores $r=0.7$. In 78 clinically normal knees, 50 had normal US scans, 21 had mild effusions and 7 had moderate effusions. Of the 18 patients with oligoarticular disease, synovial hypertrophy was more marked in the 9 patients who required repeat IA steroid injections.

\section{Conclusion}

There was good correlation between clinical and US findings. However $36 \%$ of clinically normal knees had evidence of effusion on ultrasound suggesting that ultrasound is indeed more accurate and may be of value in determining disease classification. Detection of disease activity by US, in particular synovial hypertrophy may prove a useful indicator for recurrent disease. 